\title{
UV effects on photosynthesis, growth and acclimation of an estuarine diatom and cryptomonad
}

\author{
Elena Litchman ${ }^{1,2,3, *}$, Patrick J. Neale ${ }^{1}$ \\ ${ }^{1}$ Smithsonian Environmental Research Center, PO Box 28, Edgewater, Maryland 21037, USA \\ ${ }^{2}$ School of Biology, 310 Ferst Drive, Georgia Institute of Technology, Atlanta, Georgia 30332, USA \\ ${ }^{3}$ Present address: Kellogg Biological Station, Michigan State University, Hickory Corners, Michigan 49060, USA
}

\begin{abstract}
Ultraviolet (UV) radiation is a significant stressor in aquatic environments and can inhibit primary productivity of phytoplankton. The effects of UV depend on many factors, including phytoplankton community composition and acclimation status. Using spectrally resolved biological weighting functions (BWFs), we determined sensitivity of photosynthesis and acclimation to UV in a common estuarine diatom, Thalassiosira pseudonana (Hustedt) Hasle et Heimdal, and cryptomonad, Cryptomonas sp. Cryptomonas sp. grown under high PAR (photosynthetically active radiation) (250 $\mu \mathrm{mol}$ quanta $\mathrm{m}^{-2} \mathrm{~s}^{-1}$ ) was significantly more sensitive to photoinhibition in the UV-B part of the spectrum $(280$ to $320 \mathrm{~nm})$ than T. pseudonana under high PAR. Growth under low irradiance $(25 \mu \mathrm{mol}$ quanta $\mathrm{m}^{-2} \mathrm{~s}^{-1}$ ) increased sensitivity of $T$. pseudonana. After a week-long exposure to moderate UV radiation, sensitivity of Cryptomonas sp. declined, while sensitivity of $T$. pseudonana did not change. Growth rates and chlorophyll a-specific absorption decreased in both species. Based on the BWFs obtained in this study, we predict 11 to $26 \%$ UV inhibition of depth-integrated primary production by these species under summer conditions in a shallow, turbid temperate estuary.
\end{abstract}

KEY WORDS: Estuarine phytoplankton · UV radiation $\cdot$ Photosynthesis $\cdot$ Photoinhibition $\cdot$ Biological weighting functions · Acclimation · Thalassiosira pseudonana $\cdot$ Cryptomonas sp.

\section{INTRODUCTION}

Solar ultraviolet radiation (UV) (290 to $400 \mathrm{~nm}$ ) strongly impacts major physiological processes in phytoplankton, such as photosynthesis and growth. Inhibition of photosynthesis by UV may decrease primary productivity on local and global scales and therefore should be quantified. Estimating the effects of UV is complicated by variations in sensitivity among phytoplankton and a strong spectral dependence of inhibition. In addition to differences in sensitivity, species may differ in their acclimation capabilities (Roy 2000). Polychromatic biological weighting functions (BWFs) quantifying spectral distribution of the biological response, e.g. inhibition of photosynthesis, are essential for predicting the UV effects correctly (Cullen et al. 1992, Neale 2001). The BWF approach also provides detailed information on the differences in sensitivity across the whole UV spectrum when individual
BWFs for different species or assemblages are compared. For phytoplankton in culture, the BWFs for inhibition of photosynthesis have been obtained for 3 species of dinoflagellates grown under different environmental conditions (high or low light and nutrientreplete or limited conditions) (Cullen et al. 1992, Neale et al. 1998a, Litchman et al. 2002), a diatom (Cullen et al. 1992), and 2 species of picophytoplankton (Sobrino et al. 2005). BWFs have also been determined for natural phytoplankton assemblages from different marine and freshwater environments, including Southern Ocean, subtropical ocean, a temperate estuary and freshwater lakes (Neale et al. 1998b, Banaszak \& Neale 2001, Neale 2001). The UV-sensitivity of photosynthesis varies by up to 10 -fold (Neale 2001). With more BWFs for different species, taxa and environments available, some general trends are emerging: a comparison of the BWFs of both natural communities and laboratory cultures revealed that dinoflagellates 
appear to be relatively resistant to UV. Low light conditions tend to increase sensitivity to UV, as was found for a dinoflagellate grown under high and low light (Neale et al. 1998a) and for natural communities from shallow and deeply mixed water columns (Neale et al. 1998b).

However, there are still considerable gaps in our knowledge on UV sensitivity among different species and taxa. For example, no BWF is available for some major groups of phytoplankton such as photosynthetic flagellates, including cryptophytes. Measurements of the BWF for the natural estuarine communities dominated by cryptophytes suggest that they are highly sensitive to UV compared to dinoflagellate-dominated communities (Banaszak \& Neale 2001). Other studies have also shown that cryptophytes tend to be highly sensitive to UV (Gerber \& Häder 1995). Because cryptophytes can be a significant component of phytoplankton in many environments, including coastal ocean and estuaries, it is important to be able to predict the effects of UV on this group of phytoplankton, using the BWF approach.

Although a BWF is available for a diatom (Cullen et al. 1992), the interspecific variation in UV-sensitivity within this taxon is unknown. There are also few comparisons of the impact of UV on photosynthesis and growth rate (Vernet 2000). The best approach to filling these knowledge gaps is to obtain the BWFs for natural assemblages from various environments and laboratory cultures. We determined the BWFs for inhibition of photosynthesis in a diatom and a cryptomonad grown under PAR only and compared their sensitivity; we then determined their acclimation capabilities to moderate chronic UV exposure.

\section{MATERIALS AND METHODS}

Culture growth conditions. Thalassiosira pseudonana (Hustedt) Hasle et Heimdal (Clone 3H, CCMP 1335) was obtained from the Provasoli-Guillard National Center for Culture of Marine Phytoplankton (CCMP), and Cryptomonas sp. was isolated from the Chesapeake Bay, USA, by Dr. D. Wayne Coats, Smithsonian Environmental Research Center. The cultures were grown in monocultures in semi-continuous regime (daily dilutions with the dilution rate calculated as $-\ln (f)$, where $f$ is the remaining volume expressed as a fraction of the original volume). The dilution rates for T. pseudonana were ca. 0.6 and $0.3 \mathrm{~d}^{-1}$ for the PAR only and PAR+UV treatment, respectively. The dilution rates for Cryptomonas sp. were 0.55 and $0.25 \mathrm{~d}^{-1}$ for the PAR only and PAR+UV treatment, respectively. The medium was a standard 'f/2' enrichment (Guillard 1975) of the filtered Gulf Stream seawater diluted to
$15 \%$, the typical salinity of Chesapeake Bay. For each treatment (PAR only, PAR+UV and low PAR [ $T$. pseudonana only]) duplicate cultures of each species were grown in $500 \mathrm{ml}$ teflon (PTFE) bottles at $20^{\circ} \mathrm{C}$. PAR was provided by cool-white fluorescent lights on a $14 \mathrm{~h}$ light:10 h dark cycle at $250 \mu \mathrm{mol} \mathrm{m}^{-2} \mathrm{~s}^{-1}\left(54.3 \mathrm{~W} \mathrm{~m}^{-2}\right.$, using a 4.6 conversion factor for fluorescent lights; Neale et al. 1998a). The daily PAR value and incubation temperature were similar to the in situ conditions in the spring in Rhode River, a shallow sub-estuary of Chesapeake Bay (Banaszak \& Neale 2001). PAR was measured with a quantum $4 \pi$ sensor (QSL-100, Biospherical Instruments) in the bottle with the growth medium. T. pseudonana cultures were bubbled with air to prevent carbon limitation. Cryptomonas sp. cultures were not bubbled because the densities were not high and to avoid possible detrimental effects of bubbling (common for flagellate forms). The BWF experiments were performed on each of the duplicate cultures after at least $1 \mathrm{wk}$ of semi-continuous regime under the relevant light treatment. For both the PAR only and PAR+UV treatment, the experiment was repeated 5 mo later to obtain a third replicate for each species and treatment. The irradiance for the UV treatments was supplied by fluorescent lamps UV-A 340 (Q-Panel) mounted inside the growth chamber and operated for $6 \mathrm{~h}$, centered around the middle of the light period. The UV was measured with a scanning spectroradiometer system calibrated with the NISTtraceable $1000 \mathrm{~W}$ lamp. Several measurements were made at each position outside the bottle with the sensor facing different directions and the resulting spectral irradiance was calculated (Fig. 1). To correct for bottle attenuation, spectral irradiance was also measured in the bottle, compared to measurements made without the bottle at the same position and angle, and the bottle correction factor determined. The UV levels were chosen to resemble the levels in natural conditions. In the Rhode River, a sub-estuary of Chesapeake Bay, the attenuation coefficients, $k_{\mathrm{d}}$ in the UV region $(325 \mathrm{~nm})$ in the summer are mostly between 6 to $8 \mathrm{~m}^{-1}$ (Neale 2001), so that the average UV levels in the water column are ca. $10 \%$ of surface levels. The average spectral irradiance in the water column $(1.5 \mathrm{~m}$ deep) of the Rhode River was determined as $E_{0}(\lambda)\left(1-\mathrm{e}^{-k(\lambda) z}\right) / k(\lambda) z$, where $E_{0}(\lambda)$ is incident surface irradiance, $k(\lambda)$ is the attenuation coefficient for a given wavelength, $\lambda$, and $z$ is depth $(1.5 \mathrm{~m})$.

Surface irradiance and spectral attenuation coefficients were determined as described below (subsection 'Impact of UV on primary production'). The unweighted UV-A (320 to $400 \mathrm{~nm}$ ) and UV-B (280 to $320 \mathrm{~nm}$ ) levels were 4.48 and $0.17 \mathrm{~W} \mathrm{~m}^{-2}$ in the Rhode River and 4.38 and $0.33 \mathrm{~W} \mathrm{~m}^{-2}$ in the UV treatments. Fig. 1 shows the spectrum used in UV treatments and 
the average irradiance in the Rhode River, both absolute and weighted by the BWF for the diatom Phaeodactylum tricornutum (Cullen et al. 1992) and by the DNA-damage-action spectrum (Setlow 1974). The total weights (inhibition index, $E_{\text {inh }}^{*}$ ), determined according to Eq. (2) (below), were 0.17 and 0.11 for the UV exper-
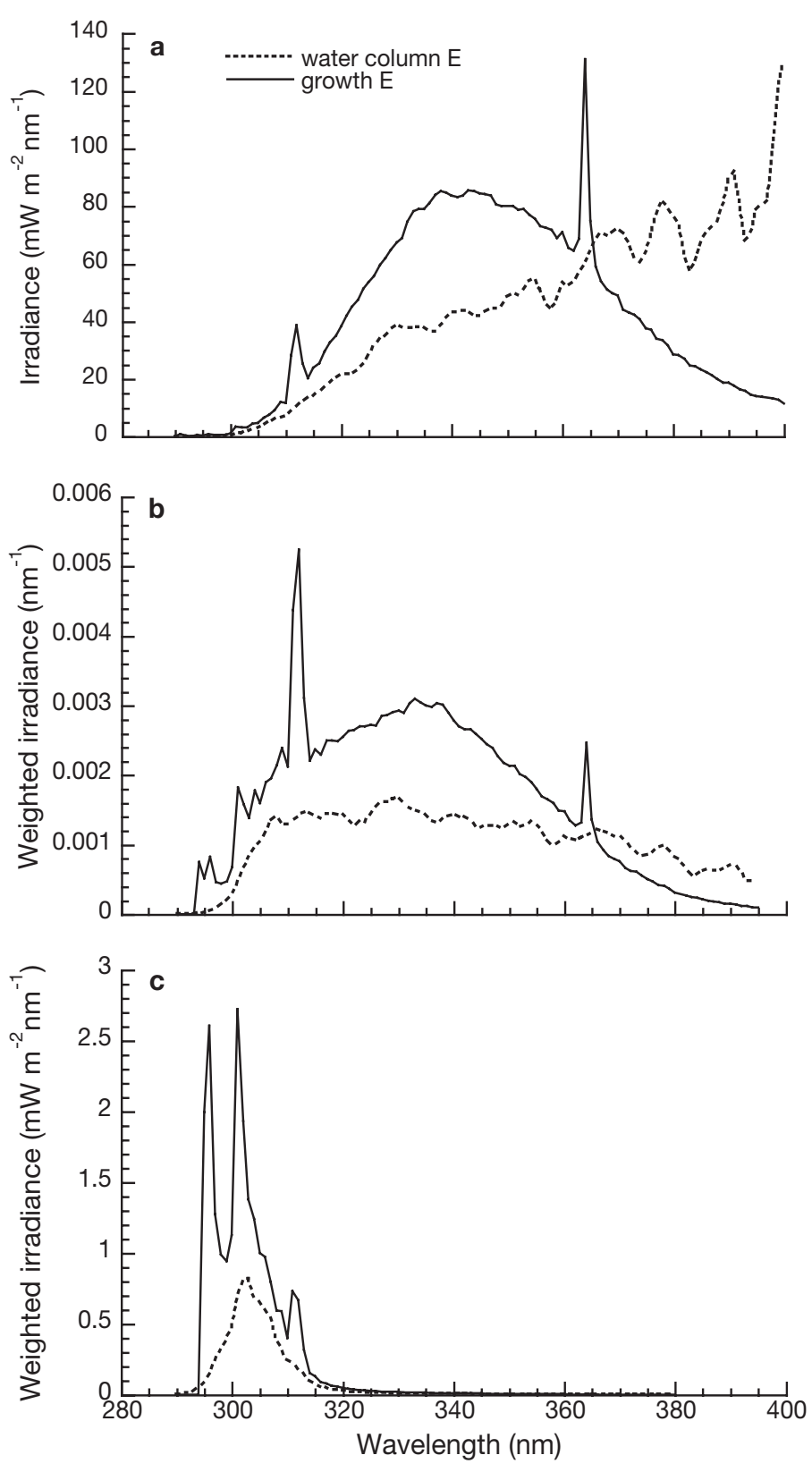

Fig. 1. Spectral distribution of UV during growth and average spectral irradiance ( 280 to $400 \mathrm{~nm}$ ) in water column of Rhode River $\left(1.5 \mathrm{~m}\right.$ deep) (near summer solstice, noon, $\left.38.9^{\circ} \mathrm{N}\right)$. (a) Unweighted radiation; (b) radiation weighted by biological weighting function (BWF) for inhibition of photosynthesis in Phaeodactylum sp. (Cullen et al. 1992); (c) radiation weighted by action spectrum for DNA damage normalized to $300 \mathrm{~nm}$ (Setlow 1974) imental treatment and the Rhode River, respectively. When weighted with the action spectrum for DNA damage (Setlow 1974), the effective irradiance, $B_{\text {effDNA }}$ (normalized to $300 \mathrm{~nm}$ ) was 23.6 and $9.3 \mathrm{~mW} \mathrm{~m}^{-2}$, for the culture UV treatment and midday (depth-averaged) Rhode River irradiance in early summer, respectively. The UV levels used in this study were also similar to the levels used in other experimental studies (e.g. Plante \& Arts 2000, Rijstenbil 2002).

Physiological parameters. Cultures were sampled every day or every other day over at least $1 \mathrm{wk}$ and cell densities were determined using a haemocytometer or Palmer-Maloney counting chamber. Growth rates were calculated as the slopes of the natural logarithms of cell densities versus time, adjusted for a dilution rate for each of the duplicate or triplicate cultures and each treatment. Cell dimensions were measured under the microscope with an ocular micrometer and cell volumes were calculated using the formula for approximating geometric figures. At least 50 cells were measured for each culture and treatment. Chlorophyll $a$ concentrations (in triplicate) were determined fluorimetrically after a $24 \mathrm{~h}$ extraction in $90 \%$ acetone in the dark at $0^{\circ} \mathrm{C}$. Particulate absorbances were measured on GF/F filters (in triplicate) using a Cary 4 dual-beam spectrophotometer. For more details on chlorophyll a and particulate absorbance measurements see Banaszak \& Neale (2001) and Litchman et al. (2002). Spectra were corrected for pathlength amplification (Cleveland \& Weidemann 1993) using a correction factor, $\beta$, of 1.5 , as determined from comparison of filters with integrating sphere measurements (Tzortziou 2004).

Biological weighting functions for inhibition of photosynthesis (BWFs). The dependence of photosynthesis on PAR and inhibition by UV radiation was measured as the uptake of $\mathrm{H}^{14} \mathrm{CO}_{3}{ }^{-}$under 72 spectral treatments (8 UV cutoffs, each with 9 irradiance levels) during a $1 \mathrm{~h}$ exposure to a Xe (solar simulator) lamp (Neale et al. 1998a). Incubation temperature was $20^{\circ} \mathrm{C}$. BWFs were determined from the measured rates of photosynthesis using the principal component analysis as previously described (Cullen et al. 1992). The data were fitted to the following equation $\left(\mathrm{BWF}_{E} / P-I\right.$ model):

$$
P^{B}=P_{\mathrm{S}}^{B}\left(1-\mathrm{e}^{-E_{\mathrm{PAR}} / E_{\mathrm{S}}}\right) \frac{1}{1+E_{\text {inh }}^{*}}
$$

where $P^{B}$ is the rate of photosynthesis normalized to chorophyll (chl) a content ( $\left.\mathrm{gC} \mathrm{g} \mathrm{chl} a^{-1} \mathrm{~h}^{-1}\right), P_{\mathrm{S}}^{B}$ is a saturated rate of photosynthesis in the absence of photoinhibition, and $E_{\mathrm{S}}$ is a saturation parameter for PAR irradiance $\left(E_{\mathrm{PAR}}, \mathrm{W} \mathrm{m}{ }^{-2}\right) . E_{\mathrm{inh}}^{*}$ is a dimensionless inhibition index defined as:

$$
E_{\text {inh }}^{*}=\sum_{\lambda=280}^{400} \varepsilon(\lambda) E(\lambda) \Delta(\lambda)
$$


where $\varepsilon(\lambda)$ is biological weight (reciprocal $\mathrm{mW} \mathrm{m}^{-2}$ ) at wavelength $\lambda(\mathrm{nm})$ and $E(\lambda)$ is spectral irradiance at $\lambda\left(\mathrm{mW} \mathrm{m}^{-2} \mathrm{~nm}^{-1}\right)$. We used the irradiance $(E)$-based model that assumes active repair (Neale 2000), as supported by the kinetics data (E. Litchman \& P. J. Neale unpubl.). BWFs were estimated for each experiment and the mean BWF was calculated for each treatment (PAR only, PAR+UV and low PAR, $\mathrm{n}=3$ for each treatment, except for the low-PAR treatment of Thalassiosira pseudonana $[\mathrm{n}=2]$ ), with confidence limits for the mean derived from individual error estimates by propagation of errors (Bevington 1969). The biological weights at $310 \mathrm{~nm}$ were compared between treatments using a Student's $t$-test.

Better resolution, PAR only, photosynthesis-irradiance $(P-I)$ curves were obtained as described in Neale at al. (1998a) in parallel with each BWF run, using a modified photosynthetron (Lewis \& Smith 1983). Photosynthetic parameters $\left(P_{\mathrm{S}}^{B}\right.$ and $\left.E_{\mathrm{S}}\right)$ were determined by fitting Eq. (1) to the data with $E_{\text {inh }}^{*}=0$. The mean photosynthetic parameters for each species and treatment were determined by averaging the values from each replicate for each treatment.

Impact of UV on primary production. We calculated the potential rates of photosynthesis for the 2 species in an estuarine environment using the BWFs according to Eqs. (1) \& (2). Incident solar UV-B radiation at the surface was measured by the Smithsonian SR18 UV-B spectroradiometer, which has 18 channels in the wavelength range of 290 to $324 \mathrm{~nm}$, defined by approx. $2 \mathrm{~nm}$ bandwidth FWHM (full width of halfmaximum transmission) interference filters. Measurements were made at the Smithsonian Environmental Research Center and averaged for solar noon (Neale 2001). Then, clear-sky spectral irradiances (UV-A and PAR) were calculated using a radiative transfer model (Ruggaber et al. 1994) implemented by the STAR software package (H. Schwander, University of Munich) for $38.9^{\circ} \mathrm{N}$ at summer solstice, midday. These values were adjusted to agree with the SR18 at $320 \mathrm{~nm}$, so that the combination of measured UV-B radiation and modeled UV-A radiation described the overall spectral irradiance distribution from 290 to $400 \mathrm{~nm}$. Additional technical details on the SR18 and a validation of the radiative transfer approach are given by Neale et al. (2005). Attenuation coefficients in the Rhode River, a shallow sub-estuary of the Chesapeake Bay, were calculated from depth profiles of spectral irradiance and used to estimate in situ spectral irradiance at $10 \mathrm{~cm}$ intervals from 0 to $1.5 \mathrm{~m}$ (average depth in Rhode River), after correcting for surface reflection (Neale et al. 1998b, Neale 2001). Average midday spectral irradiance over the June to July 1999 period (29 d) and average spectral attenuation coefficients (16 depth profiles) were used to esti- mate in situ rates of photosynthesis. Surface- and depth-integrated rates of photosynthesis for the relevant conditions were expressed as a percentage of the maximal possible rate of photosynthesis in the absence of UV.

\section{RESULTS}

\section{UV-sensitivity of photosynthesis}

Both species were sensitive to UV-A and UV-B, with a greater sensitivity in the UV-B region (Fig. 2). Cryptomonas sp. grown under PAR only was significantly

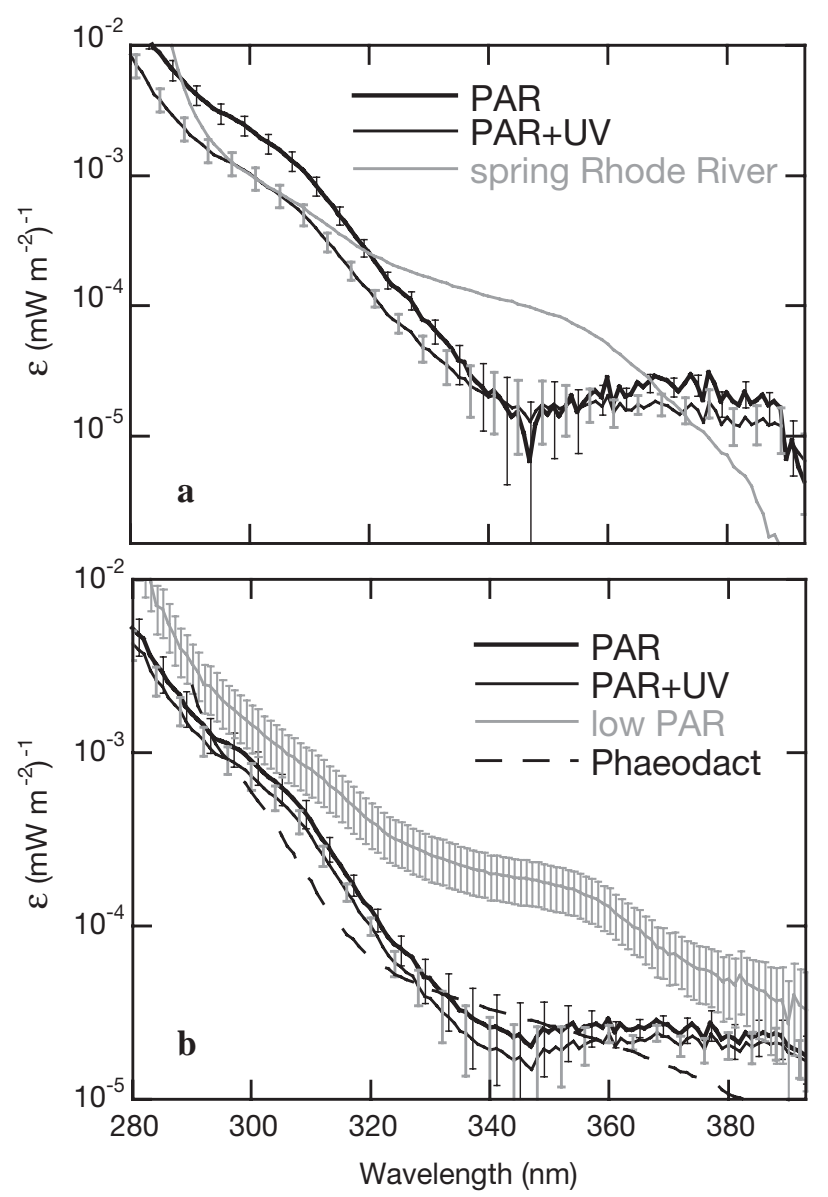

Fig. 2. (a) Cryptomonas sp. and (b) Thalassiosira pseudonana. BWFs (means $\pm \mathrm{SE}$ ) for inhibition of photosynthesis. For clarity, only limited number of error bars are plotted for some BWFs, but these show typical range over each wavelength region. Cultures grown under PAR only (thick black line, black error bars) $=250 \mu \mathrm{mol}$ quanta $\mathrm{m}^{-2} \mathrm{~s}^{-1}$; PAR+UV (thin black line, grey error bars) and low PAR (grey line, grey error bars) ( $T$. pseudonana only) $=25 \mu \mathrm{mol}$ quanta $\mathrm{m}^{-2} \mathrm{~s}^{-1}$. Panel (a) also shows average spring BWF $(n=3)$ for Rhode River assemblage dominated by Cryptomonas sp. (Banaszak \& Neale 2001), and (b) BWF for Phaeodactylum sp. (Cullen et al. 1992) 


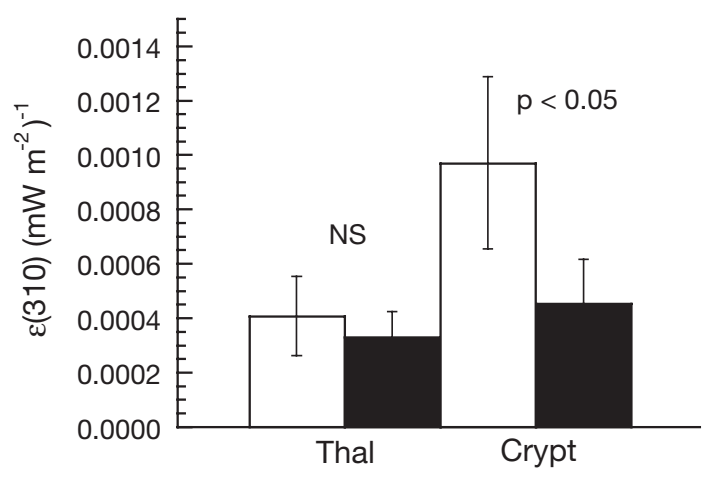

Fig. 3. Cryptomonas sp. and Thalassiosira pseudonana. Spectral weights (mean $\pm 95 \% \mathrm{CI}$ ) for inhibition of photosynthesis at $310 \mathrm{~nm}$ for phytoplankters grown under PAR only (open bars) and PAR+UV (black bars); 2 treatments were compared for each species using Student's $t$-test; NS: not significant $(\mathrm{p}>0.05)$

more sensitive in the UV-B region than Thalassiosira pseudonana grown under the same irradiance (PAR only), as seen from the BWF comparison (Figs. 2 \& 3). In the UV-A region, the BWFs of the 2 species were very similar. The chronic exposure (1 wk) to moderate UV caused a significant decrease in the sensitivity of Cryptomonas sp. in the UV-B region (Figs. 2a \& 3). In contrast, the same UV treatment did not cause a significant change in sensitivity in T. pseudonana (Figs. 2b \& 3). We hypothesized that under the given PAR, the UVsensitivity of the diatom was already low and, therefore, additional acclimation did not occur. To test the effect of PAR levels on sensitivity, we compared the sensitivity of $T$. pseudonana grown under low light at 23 to $25 \mu \mathrm{mol} \mathrm{m} \mathrm{m}^{-2} \mathrm{~s}^{-1}\left(5.4 \mathrm{~W} \mathrm{~m}^{-2}\right)$, i.e. 10 times lower PAR and no UV, with the sensitivity of the high-lightgrown culture. As Cryptomonas sp. acclimated to UV at high PAR, we did not grow it under low PAR. The low-light-grown $T$. pseudonana culture was more sensitive across the spectrum than the high-light-grown culture (Fig. 2b). The greatest relative increase in sen- sitivity was in the UV-A region (320 to $400 \mathrm{~nm}$ ): the biological weights for inhibition of photosynthesis increased 4 to 9 times under low light. Overall, the $\mathrm{BWF}_{E} / P-I$ model gave a good fit to the UV- and PARdependent photosynthesis in these cultures, with $\mathrm{R}^{2}$ in the range of 0.85 to 0.95 .

\section{Other physiological parameters}

Thalassiosira pseudonana had higher growth rate under PAR than Cryptomonas sp. The growth rates of both species decreased under moderate chronic UV exposure, with the decrease greater in $T$. pseudonana than in Cryptomonas sp. (Table 1) To estimate whether the reduction in growth rates in the UV treatment was proportional to the UV inhibition of photosynthesis, we calculated the relative decrease in photosynthesis under the UV levels during growth according to Eqs. (1) \& (2), using the BWFs of the PAR-grown cultures. Visible radiation did not cause photoinhibition in experimental cultures, as determined in PAR-only exposures in the photosynthetron. The UV levels during growth would cause daily photosynthesis to decrease to 0.9 of daily photosynthesis in the PAR-only culture in both T. pseudonana and Cryptomonas sp. These decreases can be compared to the observed growth rate decreases down to 0.4 and 0.79 of the PARonly growth rates for T. pseudonana and Cryptomonas sp., respectively.

The chl a-specific particulate absorbances also decreased under UV exposure. The low-PAR-grown Thalassiosira pseudonana culture had the lowest particulate absorbance of the T. pseudonana cultures (Fig. 4). HPLC analysis showed that cultures of the 2 species did not contain appreciable amounts of mycosporinelike amino acids, even after exposure to UV (A. Banaszak pers. comm.). The component in Cryptomonas sp. accounting for the large absorbance peak at $300 \mathrm{~nm}$ is unknown, but since it decreases in the PAR+UV cul-

Table 1. Cryptomonas sp. and Thlassiosira pseudonana. Physiological parameters (mean \pm SE) of phytoplankters grown under

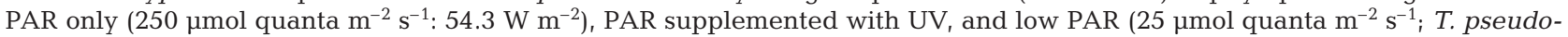
nana only). $P_{\mathrm{S}}^{B}$ (saturated rate of photosynthesis measured in absence of photoinhibition) and $E_{\mathrm{S}}$ (saturation parameter for PAR irradiance) were estimated from PAR-only incubations in the photosynthetron. $\mathrm{R}^{2}$ : proportion of variance in photosynthesis explained by fit of $P-I$ curve

\begin{tabular}{|c|c|c|c|c|c|c|}
\hline Treatment & Growth rate $\left(\mathrm{d}^{-1}\right)$ & Chl a (pg cell-1) & Cell volume $\left(\mu \mathrm{m}^{3}\right)$ & $P_{\mathrm{S}}^{B}, \mathrm{mgC}(\mathrm{mg} \mathrm{chl} \mathrm{h})^{-1}$ & 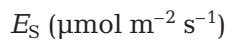 & $\mathrm{R}^{2}$ \\
\hline \multicolumn{7}{|c|}{ Cryptomonas sp. } \\
\hline PAR & $1.32 \pm 0.11$ & $1.12 \pm 0.29$ & $178.3 \pm 27.8$ & $7.4 \pm 2.2$ & $298.0 \pm 18.0$ & 0.98 \\
\hline $\mathrm{PAR}+\mathrm{UV}$ & $1.05 \pm 0.24$ & $1.7 \pm 0.01$ & $159.6 \pm 32.7$ & $6.1 \pm 2.4$ & $257.3 \pm 11.3$ & 0.98 \\
\hline \multicolumn{7}{|c|}{ T. pseudonana } \\
\hline PAR & $1.66 \pm 0.12$ & $0.16 \pm 0.001$ & - & $5.9 \pm 1.7$ & $176.6 \pm 52.9$ & 0.97 \\
\hline $\mathrm{PAR}+\mathrm{UV}$ & $0.64 \pm 0.05$ & $0.21 \pm 0.023$ & - & $5.3 \pm 0.95$ & $164.2 \pm 20.2$ & 0.97 \\
\hline Low PAR & $0.57 \pm 0.08$ & $0.32 \pm 0.005$ & - & $5.8 \pm 0.7$ & $209 \pm 10.6$ & 0.98 \\
\hline
\end{tabular}



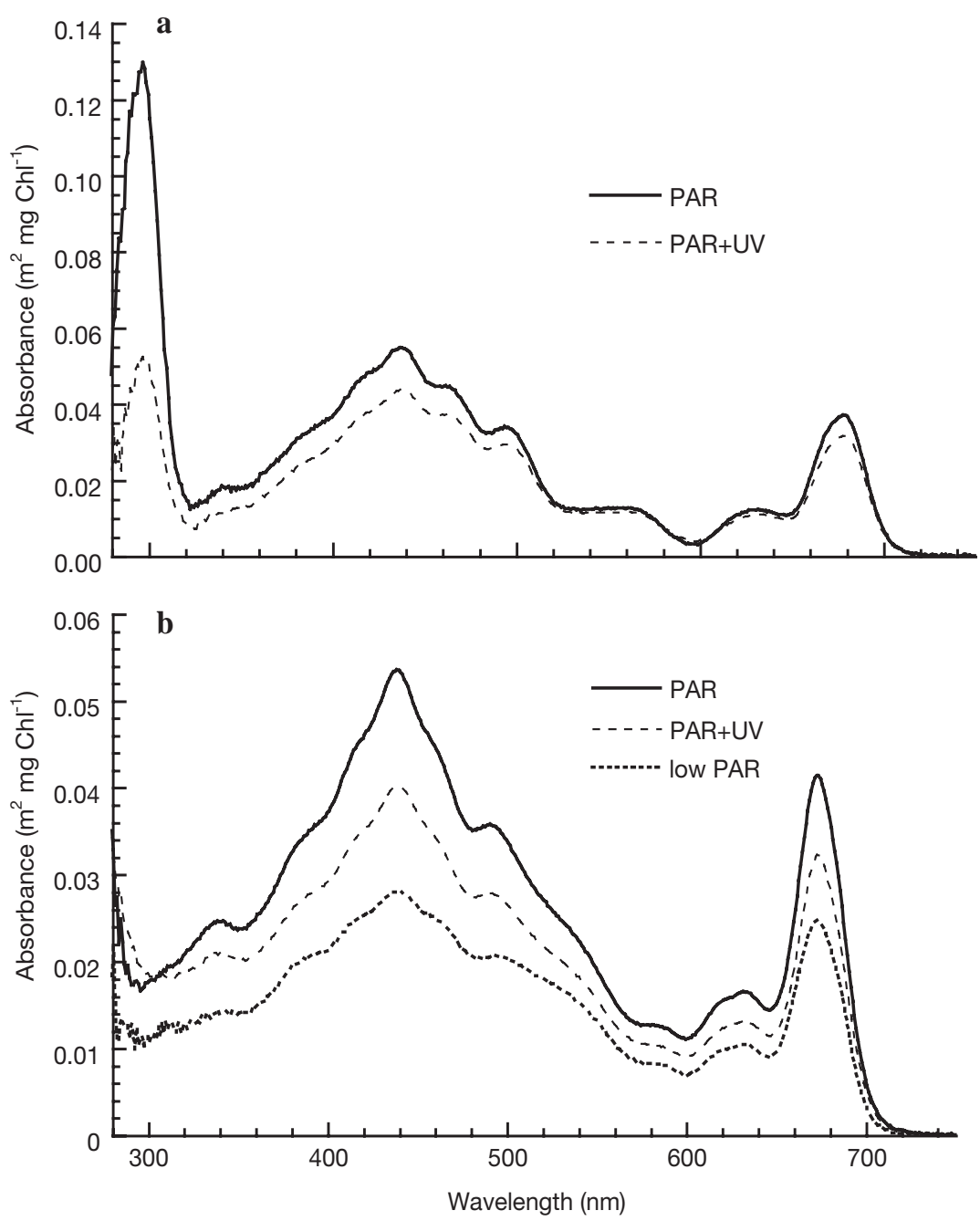

Fig. 4. (a) Cryptomonas sp. and (b) Thalassiosira pseudonana. Chlorophyll a-specific particulate absorbances of phytoplankters grown under PAR only, PAR with UV and low PAR (T. pseudonana only)

ture it does not appear to be associated with any protective mechanism.

In both species, the average cellular chlorophyll a was slightly higher in cultures grown under PAR+UV, but the difference was not significant. The low-light cultures of Thalassiosira pseudonana had significantly higher $(\mathrm{p}<0.05)$ cellular chlorophyll a than the highlight cultures.

\section{Impact of UV on primary production}

UV radiation levels typical for temperate shallow estuarine waters would decrease rates of photosynthesis in both species. The greatest reduction in photosynthesis compared to the rates in the absence of UV is predicted for Thalassiosira pseudonana grown under
low-PAR conditions and exposed to surface irradiance (Table 2). Its depth-integrated rate of photosynthesis relative to the rate in the absence of UV would also be the lowest of all cultures. The UV would inhibit the least T. pseudonana and Cryptomonas sp. grown under $\mathrm{UV}_{\text {; }}$ this is the case for both their surface- and depth-integrated rates of photosynthesis (Table 2).

\section{DISCUSSION}

\section{Biological weighting functions}

This study presents the first biological weighting function for inhibition of photosynthesis by UV for a cryptomonad, Cryptomonas sp. In agreement with the results of other studies that used broad-band exposures (Gerber \& Häder 1995), the cryptomonad is highly sensitive to UV across the spectrum, especially in the UV-B region. The diatom Thalassiosira pseudonana was significantly less sensitive to UV-B than the cryptomonad when grown under PAR only (Fig. 3). This is similar to the taxonomic trends in sensitivity found for Antarctic phytoplankton (Vernet 2000). In another study, under long-term exposure to UV, the proportion of diatoms in natural Antarctic phytoplankton communities increased and that of flagellates decreased, indicating higher UV-sensitivity of flagellates (Villafañe et al. 1995). A freshwater Cryptomonas species was also more sensitive to UV compared to green algae (Gerber \& Häder 1995). The BWFs for the natural phytoplankton assemblages from the Rhode River (Bana-

Table 2. Cryptomonas sp. and Thlassiosira pseudonana. Predicted midday rates of photosynthesis at surface and integrated over $1.5 \mathrm{~m}$ depth in Rhode River, a subestuary of Chesapeake Bay, as a fraction of $P_{\mathrm{S}}^{B}$ or depth-integrated photosynthesis in absence of UV for surface and depth-integrated values, respectively

\begin{tabular}{|lcc|}
\hline Treatment & Surface & Depth-integrated \\
\hline Cryptomonas sp. & & \\
PAR & 0.35 & 0.84 \\
UV & 0.47 & 0.88 \\
Thalassiosira & & \\
PAR & 0.41 & 0.87 \\
UV & 0.46 & 0.89 \\
Low PAR & 0.15 & 0.74 \\
\hline
\end{tabular}


szak \& Neale 2001, Neale 2001) are also consistent with our results. The cryptomonad-dominated communities were the most sensitive compared to diatom- or dinoflagellate-dominated communities (Banaszak \& Neale 2001). The average BWF of the cryptophytedominated communities indicates similar or even greater sensitivity than the culture of Cryptomonas sp. (Fig. 2a).

Thus, elevated UV through ozone depletion or changes in dissolved organic carbon concentration (Pienitz \& Vincent 2000) could affect cryptomonads to a greater degree than diatoms or dinoflagellates. It is possible that the preferred ecological strategy for flagellates and other motile phytoplankton is to avoid UV rather than maintain defenses. This may explain the higher UV-sensitivity of flagellates. However, UV has been shown to decrease motility of Cryptomonas sp. (Ekelund 1992) and other flagellate forms (Häder et al. 1995), which would interfere with an avoidance strategy (Roy 2000). As our study indicates, the cryptomonad is capable of acclimation to UV: the biological weights for inhibition of photosynthesis in the UV-B region $(310 \mathrm{~nm})$ decreased more than 2 -fold after a $10 \mathrm{~d}$ exposure to moderate UV (Fig. 3). Such acclimation would be beneficial if the phytoplankter were trapped in the upper part of the water column and its avoidance mechanisms were impaired (Vernet 2000). The acclimation of Cryptomonas sp. to UV, i.e. its decreased sensitivity following UV exposure, was observed only in the UV-B part of the spectrum; the differences between the BWFs of the PAR- versus UVgrown cultures were significant only in the UV-B region (Fig. 2).

In this study, we used the model of UV inhibition of photosynthesis, which assumes active repair that counteracts damage ('E model'; Neale 2000), as data on inhibition kinetics show that a steady-state rate was attained during UV exposure and that active recovery occurred afterwards (E. Litchman \& P. J. Neale unpubl.). The $E$ model has been successful in predicting the UV impact on primary production for phytoplankton from diverse marine, estuarine and freshwater environments (Neale 2000, Köhler et al. 2001). When the rates of recovery from UV are variable and slow, a more complicated model may be needed (Hiriart-Baer \& Smith 2004).

Difference between the 2 species was not only in sensitivity per se, but in the ability to acclimate to a given UV exposure: while the sensitivity of the cryptomonad decreased, the diatom did not show a significant decrease in sensitivity after long-term exposure to moderate levels of UV. The acclimation capabilities may be species- or higher taxon-specific (Roy 2000). Another diatom, Phaeodactylum tricornutum, also did not acclimate to UV even after more than 5 wk UV exposure (Behrenfeld et al. 1992). Thalassiosira pseudo- nana's low sensitivity may have been caused by the relatively high PAR in our experiments, so that the additional acclimation due to UV exposure did not occur. The low-light grown T. pseudonana culture was significantly more sensitive in both the UV-A and UV-B parts of the spectrum, which indicates that high PAR levels induced increased resistance to UV. A similar increase in sensitivity for low-PAR compared to highPAR-grown cultures was observed in the dinoflagellate Gymnodinium sanguineum (Neale at al. 1998a). Moreover, natural phytoplankton samples from a deeply mixed water column (i.e., low irradiance) were also more sensitive to UV compared to assemblages from a stratified water column (Neale et al. 1998b). High PAR may reduce sensitivity to UV by stimulating both the protection mechanisms, such as synthesis of photoprotective mycosporine-like amino acids (Neale et al 1998a), and rates of repair (Shelly et al. 2003). Therefore, a decreased sensitivity to UV in phytoplankton grown under high PAR may be a universal acclimation response (Roy 2000).

The sensitivity of Thalassiosira pseudonana grown under high PAR $\left(250 \mu \mathrm{mol}\right.$ quanta $\left.\mathrm{m}^{-2} \mathrm{~s}^{-1}\right)$ was similar to the sensitivity of another diatom Phaeodactylum sp. grown under $75 \mu \mathrm{mol}$ quanta $\mathrm{m}^{-2} \mathrm{~s}^{-1}$ (Cullen et al. 1992), while the low-PAR grown $\left(25 \mu \mathrm{mol}\right.$ quanta $\mathrm{m}^{-2}$ $\mathrm{s}^{-1}$ ) T. pseudonana was significantly more sensitive (Fig. 2b). Rijstenbil (2002) showed that moderate UVA and UVB levels induce oxidative stress in cells of lowPAR grown T. pseudonana. It is possible that exposure of the low-PAR grown culture of T. pseudonana to UV during growth would decrease its sensitivity to UV. This hypothesis can be tested in future experiments.

\section{Other physiological parameters}

The lower growth rates under chronic UV exposure observed in both species are common in phytoplankton (Vernet 2000). In the present case, the lower photosynthetic performance during growth under PAR+UV exposure would be expected to result in a comparable decrease in growth rate. However, the observed decrease in the growth rates of both species was greater than the estimated decrease in their rates of photosynthesis under the experimental UV radiation, as predicted by the BWF for inhibition of photosynthesis, assuming UV inhibition for $6 \mathrm{~h}$ out of the $14 \mathrm{~h}$ light period. The relative growth rate of Cryptomonas sp. under UV was $80 \%$ of the PAR-only growth rate, compared to the predicted rate (based on photosynthesis) of 0.91. Thalassiosira pseudonana had an even greater discrepancy between the predicted rate of growth and photosynthesis: $40 \%$ vs. $91 \%$ of the PAR-only rates, respectively. The UV impact on 
other cellular processes, such as DNA damage (Buma et al. 1997), in addition to inhibition of photosynthesis, possibly contributed to the growth rate decline that exceeded the decrease in photosynthesis. The observed decline in the growth rate of $T$. pseudonana is comparable with the results of Buma et al. (1996), who reported relative growth rates that ranged from 50 to $70 \%$ of the PAR-only rate for 3 other diatoms under similar exposures (daily exposure to UV-B weighted for DNA damage, $\Sigma B_{\text {effDNA }}=0.51 \mathrm{~kJ} \mathrm{~m}^{-2} \mathrm{~d}^{-1}$ for the $6 \mathrm{~h}$ exposure in our study). The UV-induced decline in the growth rate of Cryptomonas sp. was less pronounced than in the diatom $(80 \%$ of the PAR-only growth rate). Similar to previous studies, our findings indicate that the UV effects on growth rates cannot always be predicted from the photosynthetic responses to UV and that the relationship between UV inhibition of growth and photosynthesis may be species-specific (Vernet 2000).

Both species had a lower chlorophyll $a$-specific particulate absorbance after chronic UV exposure (Fig. 4). The decrease was not very pronounced and is unlikely to have been associated with a pigment bleaching, as the relative shape of the absorbance curve in the UV treatment is similar to that in the PAR-only treatment (particulate absorbance curves were almost identical after normalizing to the chlorophyll peak at $665 \mathrm{~nm}$ ). Most likely, this decrease is associated with an increased 'packaging' effect due to a slightly higher cellular content of chlorophyll $a$ in the UV treatment in both species (Table 1). Zündorf \& Häder (1991) found a decrease in accessory pigments in Cryptomonas maculata following UV exposure, but no change in the chlorophyll a concentration (it should be noted, however, that their treatments included a UVC component). A reduction in pigment concentration is a common physiological response to UV exposure (Vernet 2000). However, some studies report an increase in cellular chlorophyll a concentration in long-term UV treatments (e.g. Veen et al. 1997). Low-PAR grown Thalassiosira pseudonana also had a lower chlorophyllnormalized spectral absorption, and a decrease in absorption was observed for both visible and UV parts of the spectrum. A decrease in spectral absorption in the low-light culture was also observed in a dinoflagellate and was associated with a 'packaging' effect by Neale et al. (1998a).

We did not observe the increase in cell size in Cryptomonas sp. (no data for Thalassiosira pseudonana) that has been reported for some phytoplankton following chronic UV exposure (e.g. Veen et al. 1997). Possibly, the eyposure period or/and levels of UV were insufficient to cause significant differences. In contrast, Buma et al. (2000) found a significant increase in the cell size of Emiliania huxleyi after only $1 \mathrm{~d}$ exposure to a $\sum B_{\text {effDNA }}$ of $400 \mathrm{~J} \mathrm{~m}^{-2} \mathrm{~d}^{-1}$, which is lower than in our study. Interestingly, Buma et al. (2000) also noted that the increases in cellular pigment concentration and cell size of E. huxleyi were less pronounced at higher UV-B doses. The chronic UV exposure in our experiments did not induce MAA (mycosporine-like aminoacids) synthesis in the diatom, as found for other diatoms. It is possible that for a given UV level, the duration of UV exposure would have to be longer to stimulate MAA synthesis. Zudaire \& Roy (2001) observed an increase in MAA concentration in T. weissflogii after only $16 \mathrm{~d}$ comparable UV exposure.

\section{Impact of UV on primary production}

Ambient UV levels would reduce the rates of photosynthesis in both species. The largest reduction in photosynthesis compared to the rates in the absence of UV occured at the surface (Table 2), from only 15 to $47 \%$ of the maximal possible rates. The depth-integrated rates of photosynthesis are predicted to be 74 to $89 \%$ of the depth-integrated rates in the absence of UV. These relative rates are comparable to the depth-integrated rates predicted using the BWFs of Rhode River phytoplankton assemblages (Banaszak \& Neale 2001, Neale 2001). The difference in the predicted rates of photosynthesis between the PAR- versus UV-grown cultures of Cryptomonas sp. is much greater for their surface than for their depth-integrated rates (Table 2). As the acclimation (decrease in sensitivity) occurred primarily in the UV-B region, and because UV-B is strongly attenuated in the water column, the difference should be greater at the surface.

This simple analysis indicates that response to UV needs to be considered in assessing primary production in shallow estuarine waters. Improved estimates will require considering the full time course of UV exposure, which was beyond the scope of this report. Another question that remains to be fully addressed is the relative importance of UV inhibition of photosynthesis versus DNA damage in mediating the impact of UV on phytoplankton growth rate. DNA damage appeared to dominate the growth response of cultures under our UV exposure conditions due to the significant exposure to short wavelength UVB from the UV-A 340 lamps. In contrast, daily exposure to UV-B weighted for DNA damage ( $\left.\sum B_{\text {effDNA }}\right)$, averages less than $0.18 \mathrm{~kJ} \mathrm{~m}^{-2} \mathrm{~d}^{-1}$ in the Rhode River (maximum period considered by Neale 2001). Thus, accumulation of DNA damage is unlikely for Rhode River phytoplankton (Buma et al. 1997); however more comparative studies of DNA damage, growth, and photosynthesis under solar and simulated solar conditions are needed. 
Acknowledgements. E.L. was supported by the Smithsonian Institution Postdoctoral Fellowship. P.J.N. acknowledges support from NSF, Biological Oceanography program (OCE9812036) and US EPA, STAR program, \# RD83087801.

\section{LITERATURE CITED}

Banaszak AT, Neale PJ (2001) UV sensitivity of photosynthesis in phytoplankton from an estuarine environment. Limnol Oceanogr 46:592-603

Behrenfeld MJ, Hardy JT, Lee H II (1992) Chronic effects of ultraviolet-B radiation on growth and cell volume of Phaeodactylum tricornutum (Bacillariophyceae). J Phycol 28:757-760

Bevington PR (1969) Data reduction and error analysis for the physical sciences. McGraw Hill, New York

Buma AGJ, Zemmelink HJ, Sjollema K, Gieskes WWC (1996) UVB radiation modifies protein and photosynthetic pigment content, volume and ultrastructure of marine diatoms. Mar Ecol Prog Ser 142:47-54

Buma AGJ, Engelen AH, Gieskes WWC (1997) Wave-length dependent induction of thymine dimers and growth rate reduction in the marine diatom Cyclotella sp. exposed to ultraviolet radiation. Mar Ecol Prog Ser 153:91-97

Buma AG, van Oijen $T$, van de Poll W, Veldhuis MJW, Gieskes WWC (2000) The sensitivity of Emiliania huxleyi (Prymnesiophyceae) to ultraviolet-B radiation. J Phycol 36: 296-303

Cleveland JS, Weidemann AD (1993) Quantifying absorption by aquatic particles: a multiple scattering correction for glass-fiber filters. Limnol Oceanogr 38:1321-1327

Cullen JJ, Neale PJ, Lesser MP (1992) Biological weighting function for the inhibition of phytoplankton photosynthesis by ultraviolet radiation. Science 258:646-650

Ekelund NGA (1992) Studies on the effects of UV-B radiation on phytoplankton of sub-Antarctic lakes and ponds. Polar Biol 12:533-537

Gerber S, Häder DP (1995) Effects of enhanced solar irradiation on chlorophyll fluorescence and photosynthetic oxygen production of 5 species of phytoplankton. FEMS Microbiol Ecol 16:33-41

Guillard RRL (1975) Culture of phytoplankton for feeding marine invertebrates. In: Smith WL, Chanley MH (eds) Culture of marine invertebrate animals. Plenum Press, New York, p 29-60

Häder DP, Worrest RC, Kumar HD, Smith RC (1995) Effects of increased solar ultraviolet radiation on aquatic ecosystems. Ambio 24:174-180

Hiriart-Baer VP, Smith REH (2004) Models for ultraviolet radiation-dependent photoinhibition of Lake Erie phytoplankton. Limnol Oceanogr 49:202-214

Köhler J, Schmitt M, Krumbeck H, Kapfer M, Litchman E, Neale PJ (2001) Effects of UV on carbon assimilation of phytoplankton in a mixed water column. Aquat Sci 63: 294-309

Lewis MR, Smith JC (1983) A small volume, short-incubation-time method for measurement of photosynthesis as a function of incident irradiance. Mar Ecol Prog Ser 13: 99-102

Litchman E, Neale PJ, Banaszak AT (2002) Increased sensitivity to ultraviolet radiation in nitrogen-limited dinoflagellates: photoprotection and repair. Limnol Oceanogr 47: 86-94

Neale PJ (2000) Spectral weighting functions for quantifying effects of UV radiation in marine ecosystems. In: De Mora SJ, Demers S, Vernet M (eds) The effects of UV radiation in the marine environment. Cambridge University Press, Cambridge, p 72-100

Neale PJ (2001) Modeling the effects of ultraviolet radiation on estuarine phytoplankton production: impact of variations in exposure and sensitivity to inhibition. J Photochem Photobiol B 62:1-8

Neale PJ, Banaszak AT, Jarriel CR (1998a) Ultraviolet sunscreens in Gymnodinium sanguineum (Dinophyceae): mycosporine-like amino acids protect against inhibition of photosynthesis. J Phycol 34:928-938

Neale PJ, Cullen JJ, Davis RF (1998b) Inhibition of marine photosynthesis by ultraviolet radiation: Variable sensitivity of phytoplankton in the Wedell-Scotia Confluence during the austral spring. Limnol Oceanogr 43:433-448

Neale PJ, Litchman E, Sobrino C, Callieri C and 6 others (2001) Quantifying the response of phytoplankton photosynthesis to ultraviolet radiation: biological weighting functions versus in situ measurements in two Swiss lakes. Aquat Sci 63:265-285

Neale PJ, Goodrich VR, Brinley WR (2005) The SmithsonianNIST-USDA-FPL network for monitoring solar ultraviolet irradiance: comparison of radiometer measurements and radiative transfer model calculations. In: Martin JW, Ryntz R, Dickie RA (eds) Service life prediction: challenging the status quo. Federation of Societies for Coatings Technology, Blue Bell, PA, p 159-170

Pienitz R, Vincent WF (2000) Effect of climate change relative to ozone depletion on UV exposure in subarctic lakes. Nature 404:484-487

Plante AJ, Arts MT (2000) Effects of chronic, low levels of UV radiation on carbon allocation in Cryptomonas erosa and competition between $C$. erosa and bacteria in continuous cultures. J Plankton Res 22:1277-1298

Rijstenbil JW (2002) Assessment of oxidative stress in the planktonic diatom Thalassiosira pseudonana in response to UVA and UVB radiation. J Plankton Res 24:1277-1288

Roy S (2000) Strategies for the minimisation of UV-induced damage. In: de Mora S, Demers S, Vernet M (eds) The effects of UV radiation in the marine environment. Cambridge University Press, Cambridge, p 177-205

Ruggaber A, Dlugi R, Nakajima T (1994) Modeling of radiation quantities and photolysis frequencies in the troposphere. J Atmos Chem 18:171-210

Setlow RB (1974) The wavelengths in sunlight effective in producing skin cancer: a theoretical analysis. Proc Natl Acad Sci USA 71:3363-3366

Shelly K, Heraud P, Beardall J (2003) Interactive effects of PAR and UV-B radiation on PSII electron transport in the marine alga Dunaliella tertiolecta (Chlorophyceae). J Phycol 39:509-512

Sobrino C, Neale PJ, Lubian LM (2005) Interaction of UVradiation and inorganic carbon supply in the inhibition of photosynthesis: spectral and temporal responses of two marine picoplankters. Photochem Photobiol 81: 384-393

Tzortziou M (2004) Measurements and characterization of optical properties in the Chesapeake Bay's estuarine waters, using in-situ measurements, MODIS satellite observations and radiative transfer modelling. $\mathrm{PhD}$ thesis, University of Maryland, College Park, MD

Veen A, Reuvers M, Ronçak P (1997) Effects of acute and chronic UV-B exposure on a green alga: a continuous study using a computer-controlled dynmaic light regime. Plant Ecol 128:29-40

Vernet M (2000) Effects of UV radiation on the physiology and ecology of marine phytoplankton. In: de Mora S, Demers $\mathrm{S}$, Vernet $\mathrm{M}$ (eds) The effects of UV radiation in the marine 
environment. Cambridge University Press, Cambridge, p 237-278

Villafañe VE, Helbling EW, Holm-Hansen O, Chalker BE (1995) Acclimatization of Antarctic natural phytoplankton assemblages when exposed to solar ultraviolet radiation. J Plankton Res 17:2295-2306

Editorial responsibility: Otto Kinne (Editor-in-Chief), Oldendorf/Luhe, Germany
Zudaire L, Roy S (2001) Photoprotection and long-term acclimation to UV radiation in the marine diatom Thalassiosira weissflogii. J Photochem Photobiol B 62:26-34

Zündorf I, Häder DP (1991) Biochemical and spectroscopic analysis of UV effects in the marine flagellate Cryptomonas maculata. Arch Microbiol 156:405-411

Submitted: May 27, 2004; Accepted: April 28, 2005

Proofs received from author(s): August 31, 2005 